\title{
EVALUATION OF ORANGE OIL APPLIED BY THREE BACKPACK SPRAYERS AGAINST AEDES AEGYPTI AND CULEX QUINQUEFASCIATUS
}

\author{
RUI-DE XUE AND ALI. FULCHER \\ Anastasia Mosquito Control District, 120 EOC Drive, \\ St. Augustine, FL 32092.
}

Guest Editor: M. Farooq

\begin{abstract}
A solvent orange oil has been used to mix with permethrin and $\mathrm{PBO}$ as a commercial adulticide product called Aqualure ${ }^{\circledR} 20-20$ for control of adult mosquitoes. The orange oil at $2.7 \%$ and $3.5 \%$ sprayed by three backpack sprayers, Hudson battery operated sprayer modified with a Solo nozzle, hand pump sprayer Solo- 425 , and Birchmeire battery operated sprayer, against caged adult female Aedes aegypti Linn. and Culex quinquefasciatus Say resulted in $89 \%-100 \%$ mortality of Ae. aegypti and $100 \%$ mortality of Cx. quinquefasciatus. The three different backpack sprayers did not show any significant differences in the percent mortality. Our test results demonstrate that orange oil alone at a high dose $(3.5 \%)$ showed effective insecticidal characteristics against both species of adult mosquitoes.
\end{abstract}

Key Words: permethrin, orange oil, adulticide, Aedes aegypti, Culex quinquefasciatus

Orange oil is an essential oil extracted from the peel of the orange fruit. The essential oils extracted from the orange plant have shown insecticidal properties against mosquitoes and other insects (Ezeonu et al. 2001, Norris et al. 2015, Badawy et al. 2018). Orange oil varies in chemical composition depending on the fruit and method of extract action. The oil not only proves to be an effective repellent, but it has also shown to be lethal to adult mosquitoes (Xue et al. 2003, Phasomkusolsil and Soonwera 2011, Badawy et al. 2018) and can act as a synergist for pyrethroid insecticides (Gross et al. 2017). Orange oil has been used to mix with permethrin and piperonyl butoxide (PBO) as Aqualure ${ }^{\circledR}$ 20-20 (All Pro Vector Group, Bloomington, MN) adulticide and marketed for adult mosquito control (Amoo et al. 2012). Recently, two new backpack sprayers operated with batteries are available commercially. The objectives of this study were to determine the orange oil's insecticidal efficacy against two species of adult mosquitoes and to evaluate the two new battery-operated backpack sprayers, compared with the standard hand-pump sprayer Solo 425® (Solo Inc., Newport News, VA) against caged adult mosquitoes.

The colonies of the Orlando strain of Ae. aegypti Linn. and the Gainesville strain of $C x$. quinquefasciatus were provided by the USDA, Center for Medical, Agricultural, and Veterinary Entomology, Gainesville, FL and reared at Anastasia Mosquito Control District (AMCD), St. Augustine, FL. Adult female mosquitoes at 5-7 days old were used for the testing.

The three backpack sprayers, Hudson battery-operated sprayer (13854 NeverPump Back-Pak ${ }^{\circledR}$, H.D. Hudson Manufacturing Co., Chicago, IL) which was modified by using an extra sprayer nozzle from Solo, hand pump sprayer Solo 425, and Birchmeier battery-operated sprayer (REC 15, Birchmeier Spruhtechnik AG, Stetten, Switzerland), described by Conover et al (2015), were calibrated and used for the testing. Distilled water was sprayed from each sprayer into a measurable plastic container for $1 \mathrm{~min}$ to quantify spray volume. The Solo sprayer was pumped every $3 \mathrm{sec}$ to maintain constant pressure while calibrating. Modified Hudson sprayer's flow rate was $728 \mathrm{~mL} / \mathrm{min}$, Solo was $693 \mathrm{~mL} / \mathrm{min}$, 
and Birchmeier was $735 \mathrm{~mL} / \mathrm{min}$. Orange oil was provided by All Pro Vector Group (Bloomington, MN). The tested solution was diluted by distilled water at the low rate $2.7 \%$ and high rate $3.5 \%$. All three sprayers produced a spray distance of approximately 2 meters. The certified applicator's walking speed was $6.4 \mathrm{~km} / \mathrm{h}$.

The study site was located in the back yard of AMCD facilities located at East Pope Road, St. Augustine, FL (29.859515, 81.279366). For each test, 12 meshscreened $(0.7 \mathrm{~mm}$ mesh size $)$ cylindrical paper cages (9 for treatments and 3 for controls) containing 10 female mosquitoes at 5-7 days old per cage transferred via mouth aspiration were used. The same number of mosquitoes and type of cages were used for each application (a total of 36 cages for 3 sprayers). The cages were adhered to vertical PVC pipes (1.5 meters) within the spray path. The 9 pipes were placed 3 meters apart. The control cage mosquitoes were placed at an appropriate distance (approximately 17 meters) outside of the spray path to prevent insecticide drift from the treatment applications. The treatment cages were sprayed from approximately 2 meters away in a waving motion while the applicator was walking at $6.4 \mathrm{Km} / \mathrm{h}$. The caged mosquitoes sat for 15 min after exposure then a knockdown count was taken. Post-exposure cages were brought back to the AMCD laboratory and maintained on a $10 \%$ sucrose solution. Mortality of mosquitoes was read at 24 hours after exposure. The same experiments were repeated three times. Weather conditions averaged $27^{\circ} \mathrm{C}$ temperature, $70 \%$ relative humidity, and 4 $\mathrm{Km} / \mathrm{h}$ wind speed.

The Fig. 1 showed that orange oil at the high dose $(3.5 \%)$ resulted in $100 \%$ mortality of Cx. quinquefasciatus at $24 \mathrm{~h}$, sprayed by all three types of backpack sprayers. The oil at the low dose $(2.7 \%)$ sprayed by Solo, Hudson, and Birchmeire sprayers against Cx. quinquefasciatus resulted in $97 \%, 91 \%$, and $84 \%$ mortality at $24 \mathrm{~h}$, respectively. The oil at the high dose sprayed by Solo, Hudson, and Bichmeire against Ae. aegypti resulted in $82 \%, 97 \%$, and $100 \%$ mortal- ity at $24 \mathrm{~h}$, respectively. The oil at the low dose $(2.7 \%)$ sprayed by Solo, Hudson, and Birchmeire sprayers against Ae. aegypti resulted in $47 \%, 76 \%$, and $71 \%$ mortality at $24 \mathrm{~h}$, respectively. It is not surprising that the high dose of orange oil at $3.5 \%$ caused significantly higher mortality $(F=4.366, P$ $<0.01$ ) of both species of mosquitoes, regardless of the types of backpack sprayer, compared with the mortality caused by the low dose at $2.7 \%$. The three types of backpack sprayers did not show any significant difference $(\mathrm{P}>0.05)$ against either species of caged mosquitoes although Solo sprayer caused lower mortality against the two species of adult mosquitoes at the high and low dose of the oils.

Norris et al (2015) reported that commercial plant essential oils possess insecticidal characteristics against adult mosquitoes. Our results support Norris et al's findings and confirm the insecticidal activity of orange oils against adult mosquitoes. Other benefit from the commercial plant essential oils is the capability of increasing the efficacy of permethrin against Ae. aegypti and Anopheles gambiae (Gross et al 2017). These factors explain why orange oils have been used for the commercial product formulation of the permethrin-based Aqualuer ${ }^{\circledR}$ 20-20 for the control of adult mosquitoes.

Back pack sprayers are convenient means for application of liquid insecticide products (Kardatzke et al. 1981, Xue et al. 2012). Conover et al (2015) reported that the three same backpack sprayers sprayed Aqualuer ${ }^{\circledR}$ 20-20 against caged Ae. aegypti resulted in no significant difference in percent mortality of the test mosquitoes between the sprayers, but the Birchmeier sprayer was the preferable machine in terms of its physical characteristics and operator use with battery. The orange oils sprayed by the three backpack sprayers against caged Ae. aegypti resulted in similar mortality and are in agreement with Conover et al (2015). Thus based on our results, either one of the three backpack sprayers could be used for adult mosquito control based on the availability and cost, but the battery-operated backpack sprayer may be more convenience. 

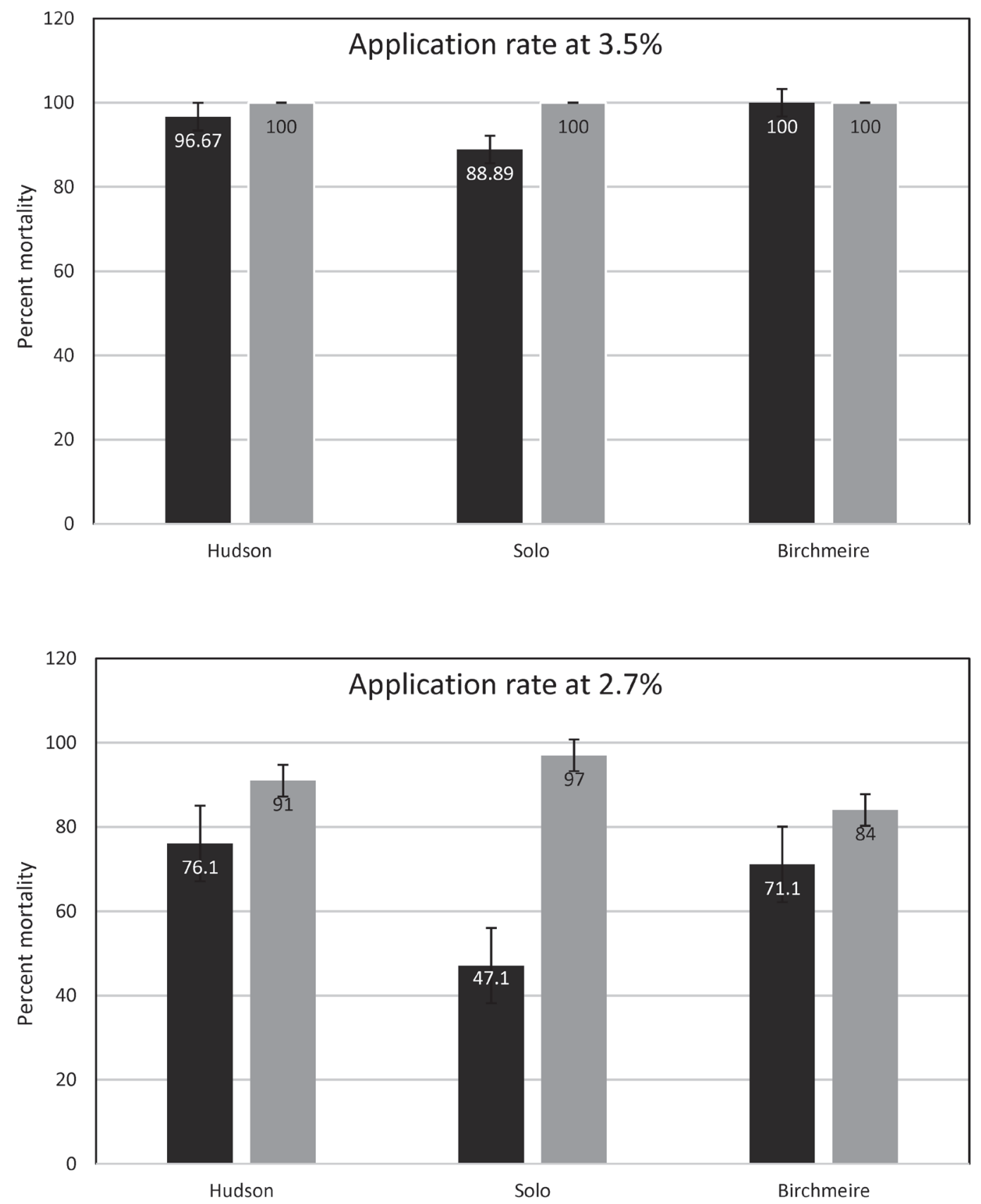

Figure 1. Mortalities (mean $\% \pm \mathrm{SE}$ ) of caged adult female Aedes aegypti (bold black) and Culex quinquefasciatus (light black) at $24 \mathrm{~h}$ after exposed to orange oils (high rate at $3.5 \%$ \& low rate $2.7 \%$ ) sprayed by three different backpack sprayers.

\section{ACKNOWLEDGMENTS}

Thanks All Pro LLC for providing the solvent orange oils for the testing, D. Conover, M.
Smith, and K. Gaines for their participations in the experiment and technical help. This is a research report only and does not mean AMCD to endorse any commercial products. 


\section{REFERENCES CITED}

Amoo AO, Xue RD, Qualls WA, Wang ZM, Zhao TY. 2012. Efficacy evaluation of three permethrin products against caged Culex quinquefasciatus. Acta Parasitol Med Entomol Sinica 19:19-24.

Badawy MEI, Taktak NEM, E-Aswad AF. 2018. Chemical composition of the essential oils isolated from peel of three citrus species and their mosquitocidal activity against Culex pipiens. Nat Prod Res 32:2829-2834.

Conover D, Fulcher A, Smith ML, Farooq M, Gaines MK, Xue RD. 2015. Evaluation of three commercial backpack sprayers with Aqualuer ${ }^{\circledR}$ 20-20 against caged adult Aedes aegypti. J Am Mosq Control Assoc 31:190-192.

Ezeonu FC, Chidumo GI, Udedi SC. 2001. Insecticide properties of volatile extracts of orange peels. Bioresour Technol 7:273-274.

Gross AD, Norris EJ, Kimber MJ, Bartholomay LC, Coats JR. 2017. Essential oils enhance the toxicity of permethrin against Aedes aegypti and Anopheles gambiae. Med Vet Entomol. 31:55-62.
Kardatzke JT, Gula PR, Nelson JH. 1981. Engineering evaluation of commercial backpack sprayer/dusters. Mosq News 41:327-330.

Norris EJ, Gross AD, Dunphy BM, Bessette S, Bartholomay L, Coats JR. 2015. Comparison of the insecticidal characteristics of commercially available plant essential oils against Aedes aegypti and Anopheles gambiae (Diptera: Culicidae). J Med Entomol 52:993-1002.

Phasomkusolsil S, Soonwera M. 2011. Efficacy of herbal essential oils as insecticide against Aedes aegypti (Linn.), Culex quinquefasciatus (Say) and Anopheles dirus (Peytonand Harrison). Southeast Asian J Trop Med Public Health 42:1083-1092.

Xue RD, Barnard DR, Ali A. 2003. Laboratory evaluation of toxicity of 16 insect repellents in aerosol sprayers to adult mosquitoes. J Am Mosq Control Assoc 19:271-274

Xue RD, Qualls WA, Smith ML, Zhao TY, Brown JR. 2012. Evaluation of Pioneer Eco-Backpack sprayer and Twister XL backpack sprayer using Aqualuer against caged Aedes albopictus and Culex quinquefasciatus. J Am Mosq Control Assoc 28:341-342. 